Research Article

\title{
Study on Release and Migration of Radionuclides under the Small Break Loss of Coolant Accident in a Marine Reactor
}

\author{
Zhao Fang $\mathbb{D}^{1,2}$ Zou Shuliang $\mathbb{D}^{1,2}$ Liu Zejun, ${ }^{3}$ Xu Tao, ${ }^{4}$ Xu Shoulong, ${ }^{1,2}$ Huang Yan, ${ }^{1,2}$ \\ and Feng Jinjun ${ }^{3}$ \\ ${ }^{1}$ School of Resource Environment and Safety Engineering, University of South China, Hengyang 421001, Hunan, China \\ ${ }^{2}$ Hunan Provincial Key Laboratory of Emergency Safety Technology and Equipment for Nuclear Facilities, Hengyang 421001, \\ Hunan, China \\ ${ }^{3}$ Nuclear and Radiation Safety Center in China, Beijing 100082, China \\ ${ }^{4}$ Science and Technology on Reactor System Design Technology Laboratory, Nuclear Power Institute of China, Chengdu 610213, \\ Sichuan, China
}

Correspondence should be addressed to Zou Shuliang; zousl2013@126.com

Received 16 December 2020; Revised 12 January 2021; Accepted 2 April 2021; Published 17 April 2021

Academic Editor: Enrico Zio

Copyright (c) 2021 Zhao Fang et al. This is an open access article distributed under the Creative Commons Attribution License, which permits unrestricted use, distribution, and reproduction in any medium, provided the original work is properly cited.

Using severe accident analysis program MELCOR, the small break loss of coolant accident (SBLOCA) analysis model was established for a marine reactor. The release and migration of radionuclides were analyzed during a severe accident induced by SBLOCA. The analysis of the hydrogen source term release showed that the maximum hydrogen release amount was $248.567 \mathrm{~kg}$, and the hydrogen release amount accounted for less than $4 \%$ of the air volume. So, there would be no danger of hydrogen explosion accidents. The research mainly focused on the behaviors of the release, the transport, the retention, and the final distribution of inert gases represented by Xe, volatile gases represented by CsI, and nonvolatile nuclides represented by Ba. The results showed that the reactor core exposed completely with a lagging by $510 \mathrm{~s}$ and the initial release time of nuclides was lagged by $1916 \mathrm{~s}$. The release shares of Xe in the primary circuit system, the containment, and the environment were $0.013 \%, 0.06 \%$, and $32.71 \%$, respectively. Also, Ba shared $0.016 \%, 0.0032 \%$, and $3.28 \%$, respectively, and CsI shared $0.0145 \%, 0.0012 \%$, and $2.845 \%$, respectively.

\section{Introduction}

The research on the source term during severe accidents in marine nuclear reactors is still insufficient. During sailing on the sea, ships driven by nuclear reactors may experience a violent rocking collision or other accidents, which may cause severe accidents in the nuclear reactors. Also, due to the small spaces and limited deadweights of the nuclear reactors, their safety facilities are usually not so perfect compared with those for stationary nuclear power plants [1]. Thus, the occurrence probability of severe accidents in marine nuclear reactors is higher than that in land-based nuclear reactors. Therefore, it is necessary to study severe accidents in marine nuclear reactors to clarify their source terms [2].
Xuefeng et al. [3] studied the hydrogen source term during a loss of coolant accident in a marine nuclear reactor and researched the hydrogen risk and the hydrogen control system in the marine nuclear reactor. The hydrogen generation rate and steam release rate are calculated, and the three-dimensional computational fluid dynamics code GASFLOW was employed to simulate the two-dimensional flow field and the transport and distribution of hydrogen in the cabin. Kehan Ouyang et al. [4] analyzed the atmospheric radioactive dispersion caused by a severe accident in a marine nuclear reactor. Based on the Lagrangian particle, a tracking model to simulate atmospheric diffusion of radionuclides above the sea was established. The influences of sea absorption on the atmospheric diffusion of radionuclides emitted at different heights were analyzed. It mainly focuses 
on the research on the diffusion of hydrogen source term and fission products outside the cabin. There were few pieces of research on the release and migration of other radionuclides in the ship's reactor cabin.

Zhang et al. [1] and Wang Wei et al. [5, 6] conducted source term analysis during a severe accident induced by large break loss of coolant caused by the whole ship blackout due to the rupture of a tube of the steam generator. They also focus on the release and migration trends of the inert gas $\mathrm{Xe}$ and the volatile gas CsI as well as the release share distribution trends in the cabin. Zhan et al. [7] analyzed the radioactive release accident caused by the interruption of power supply and safety valve failure under four operating conditions, which were 1 time, 5 times, 13 times, and reiterative times of the opening of the pressurizer safe valve. The release and migration of radionuclides emitted from a marine nuclear reactor caused by multiple severe accidents and superimposed accidents were mainly studied. But the source term analysis associated with serious accidents caused by a single small breach was not well studied.

This research analyzed a marine reactor by adopting the MELCOR [8-10]. The calculation model of the severe accident in a nuclear reactor was established to study the release and migration characteristics of radionuclides under SBLOCA.

\section{Methods}

2.1. Nodalization of Marine Reactor. The research object was a natural circulation small modular light-water reactor with the thermal power of $330 \mathrm{MW}$. The marine reactor model mainly included reactor pressure vessel (RPV), the pressure containment vessel (PCV), the containment pool (CP), the passive safety system (PSS), the pressurizer, the steam generator (SG), and the passive decay heat removal system (PDHRS). This model used 40 control volumes and 26 connection channels to simulate the main compartment divisions in the containment, as shown in Figure 1. Nodalization can reflect the release and migration of radionuclides in a marine reactor after the occurrence of an SBLOCA event. The main hydraulic regions in RPV were modeled by different control volumes, which included the reactor core (CV170), the bypass region (CV180), the upper head 1 (CV190), the upper head 2 (CV191), the pressurizer (CV500), the SG primary side (CV230-CV239), the SG secondary side (CV630-CV639), the downcomer (CV240), and the lower head (CV150). Figure 1 shows that the SG primary side and secondary side were divided into 10 nodes each along the flow direction for the detail calculation. Some regions (CV231, CV232, CV603, and CV604) at the inlet of pressurizer and the outlet of SG were also modeled for accurate modeling.

For the main steam system and PDHRS, the main steam head (CV621) and the feedwater head (CV620) were modeled. The volume in PCV consisted of the cavity (CV810) and the containment (CV830). The environment in the area outside the containment was represented by a large control volume (CV950) with constant pressure and temperature. The control volumes were connected by the flow path which is presented by arrows in the Figure 1. The valves such as the safety relief valves (SRVs), the reactor recirculation valves (RRVs), the reactor venting valves (RVVs), and main steam isolation valves were modeled in the corresponding flow path.

2.2. Nodalization of Reactor Core. More detailed nodalization of the reactor core in the MELCOR was conducted for simulating the complex physical and chemical phenomena. Figure 2 shows the core nodalization for a marine reactor. The lower plenum was simplified as a cylinder and nodalized with the reactor core and the lower head was flat as a platform. The core and lower plenum were divided into 5 concentric radial rings and 16 axial rows. The bottom four axial rows 1 to 4 represented the lower plenum, while the top rows 6 to 15 represented the active core area. Row 5 represented the lower inactive core area, and row 16 represented the higher inactive core region. The fourth row represented the core support plate which is an important key structure in the reactor core because the core support plate has a great influence on the core displacement process. The particular ring and row formed a core node or core cell (for example, node 203 meant the 2 nd ring and 3 rd row). The lower head of the marine reactor was of steel structure corresponding to the core ring. It was also divided into 5 rings.

2.3. Analysis of Accident Progress. At $500 \mathrm{~s}$, a small break loss of coolant accident occurred. The containment ruptured, and the passive decay heat removal system failed. The pressure in the main system dropped sharply, and the containment pressure increased rapidly. At the same time, the reactor was shut down due to the low pressure in the main system. When the break occurred, the primary circuit system coolant was quickly released to the reactor cabin through the break, resulting in the loss of a large amount of coolant, and a rapid drop of the water level in the reactor core. At 46,900 s, the core active area was completely exposed. After the exposure of the core, the temperature of the fuel elements and the cladding continued to rise, and the gap release phase started.

At $64,400 \mathrm{~s}$, the bottom of the core dried up, and the core support plate began to fail. When the molten core melted through the core support plate, it fell into the lower chamber and contacted the lower head to exchange heat. Then, the lower head crept and broke, and the lower head failed. The core melted and fell into the pit and the release phase outside the pressure vessel started.

The accident was initiated by the SBLOCA in the pressurizer at $500 \mathrm{~s}$. As illustrated in Figure 3, the RPV pressure quickly decreased once the RVV was opened, and the PCV pressure meanwhile increased. Large amount of core materials relocated to the lower plenum after the core support plate in different rings failed. The melt core materials, with decay heat, accumulated in the lower plenum formed a debris bed and interacted with the lower head wall, raising the wall node temperature as shown in Figure 4.

2.4. Calculation Model of Radionuclide Release. Radioactive material may be released from the core. The radionuclides residing in the core (COR) package fuel are 


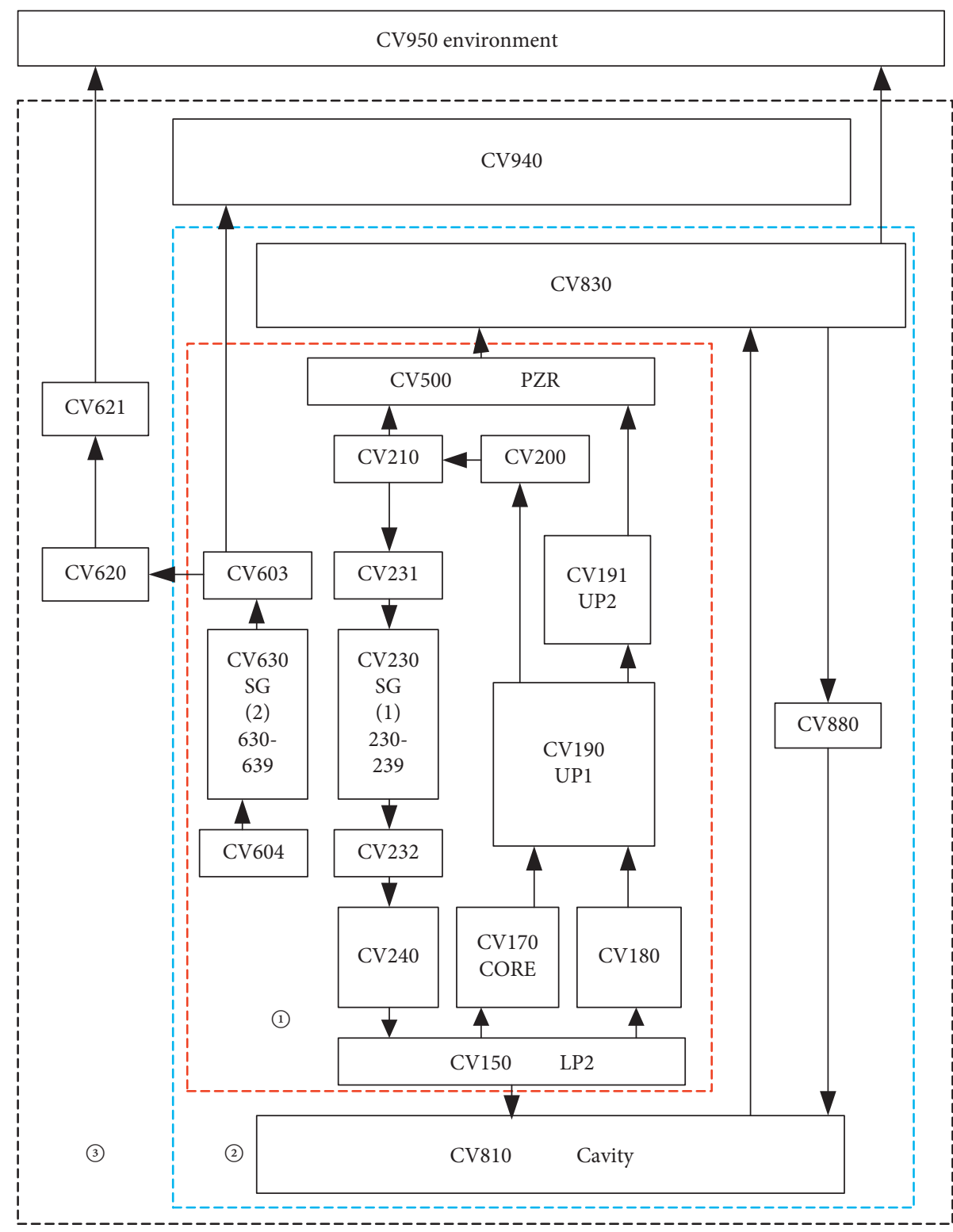

FIgURE 1: Nodalization of the marine reactor.

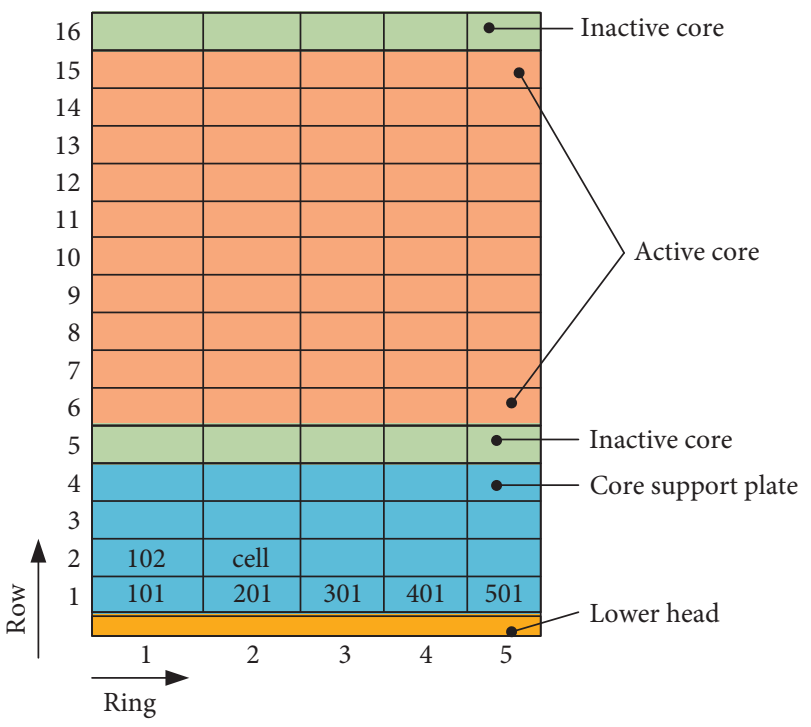

FIgURE 2: Nodalization of the core of the marine reactor. 


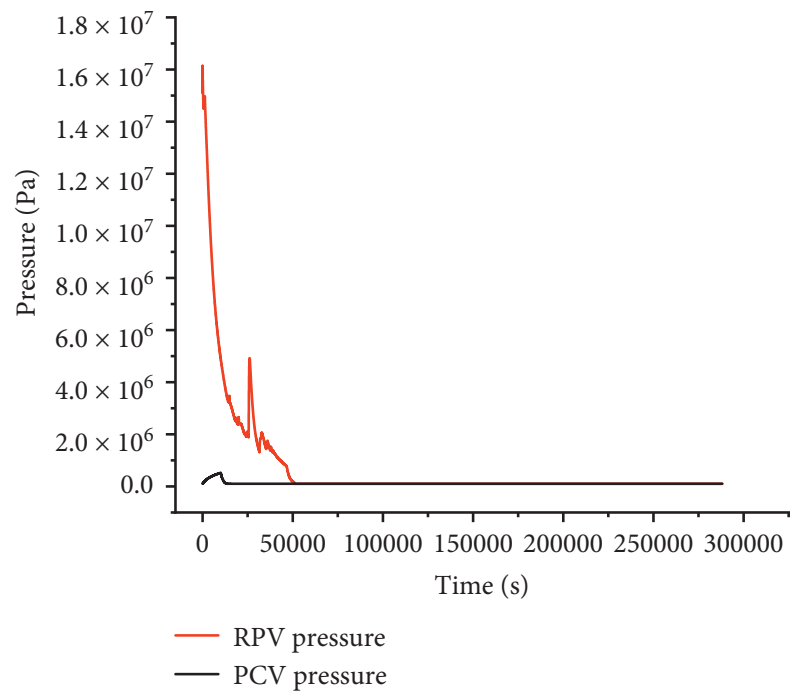

Figure 3: Pressure in PCV and RPV.

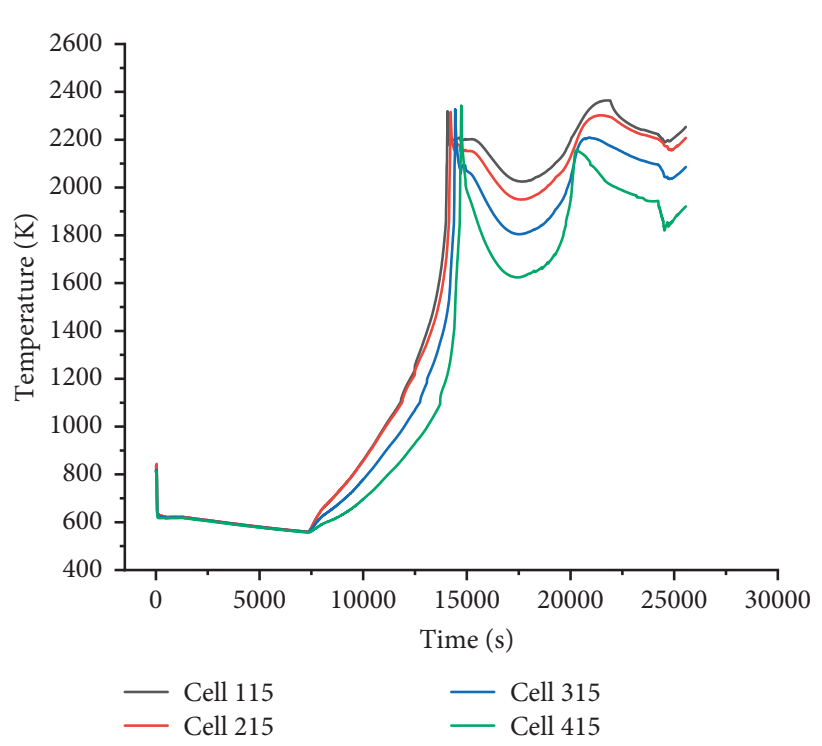

FIGURE 4: The node temperature in the outer layer.

assumed to be in elemental form and therefore to have only radioactive mass (no associated molecular mass). Upon release from fuel, the total class masses are converted to compound form with a corresponding increase in mass from the added nonradioactive material (e.g., the hydroxide mass in $\mathrm{CsOH}$ ). By default, the release models are used to calculate the release of radionuclides from core fuel material (i.e., $\mathrm{UO}_{2}$ ) only, which exists in the intact fuel component, in refrozen fuel material or in other components, and in particulate in debris.

Note that, for each core component, the same correlation is used to calculate the release rate for a given class using the individual temperature of that component. That is, the calculation of release of radionuclides from fuel, cladding, canisters, control rods, and particulate debris differs only in the temperature used.
The calculation model of the serious accident analysis program correlates with the fractional release rate in the exponential form [11]:

$$
\dot{f}=A \exp (B T) \quad \text { for } T \geq T_{i},
$$

where $\dot{f}$ is the release rate (fraction per minute), $A$ and $B$ are empirical coefficients based on experimental data. Different values for $A$ and $B$ are specified for three separate temperature ranges. $T$ is the temperature of the core unit $(\mathrm{K})$ and $T_{i}$ is the minimum temperature set by the user at the beginning of release, $(\mathrm{K})$.

\section{Accident Hypothesis and Grouping of Radionuclide}

3.1. Assumptions of Marine Reactor Design Parameters. The steady-state behavior of the marine reactor severe accident model is an important feature indicating the reliability of the model and the basis of transient accident analysis. According to the design conditions of small-scale marine pressurized water reactors, the key parameters were established to provide the initial conditions for severe accidents. These parameters were in good agreement with corresponding design values demonstrated by a comparative analysis shown in Table 1 [12]. Therefore, this steady-state can be used as the initial condition for the subsequent accident simulation.

3.2. Assumptions of Accidents. At the beginning of the accident, it was assumed that SBLOCA with an area of $0.0064 \mathrm{~m}^{2}$ occurred in the pressurizer caused by a failure in RVVs. This means that the nuclear reactor malfunctioned at the beginning of the accident. The open pressure for SRVs of PCV was $5 \mathrm{MPa}$. No operator actions or interventions were considered during the handling of the accident.

According to the information in the output file of the MELCOR code, Table 2 indicates the occurrence sequence of severe accidents [12]. Compared with severe accidents in traditional light-water reactors, some failures in the core support plate and the lower head occurred in the later stage of the accident. It is important to note again that, in the current analysis, operator actions that are beneficial to accident mitigation were not considered.

3.3. Grouping of Radionuclides. In a severe accident, the degree of fission products in the reactor core released into the containment, and the environment mainly depends on its physical and chemical properties. The MELCOR divides some elements with similar properties into 16 groups [11] as shown in Table 3 and processed them in groups. Depending on the characteristics of a marine reactor, 13 groups were selected for this study, and 3 groups of elements (boron, water, cement, and no concrete in the reactor pit) were removed.

\section{Safety Analysis of Marine Reactor}

4.1. Release Analysis of the Hydrogen Source Term. Combustion and explosion of hydrogen constitute a major threat to the integrity of the containment vessel. Hydrogen 
TABLE 1: Key parameters in steady state and design value.

\begin{tabular}{lcc}
\hline Key parameters & Designed value & $\begin{array}{c}\text { Steady-state } \\
\text { value }\end{array}$ \\
\hline Core thermal power $(\mathrm{MW})$ & 330.0 & 330.02 \\
Primary system pressure (MPa) & 12.76 & 12.85 \\
Core inlet temperature (K) & 552.15 & 552.83 \\
Core outlet temperature (K) & 583.15 & 583.42 \\
Core inlet mass flow rate (kg/s) & 1960 & 1977 \\
SG steam pressure (MPa) & 3.5 & 3.501 \\
SG steam temperature $(\mathrm{K})$ & 575.15 & 575.4 \\
SG feedwater temperature $(\mathrm{K})$ & 422.15 & 421.7 \\
Main steam mass flow rate $(\mathrm{kg} / \mathrm{s})$ & 140.0 & 140.0 \\
RPV coolant inventory $(\mathrm{kg})$ & 126340.0 & 126346.0 \\
Fuel mass inventory $(\mathrm{kg})$ & 16280.0 & 16280.0 \\
\hline
\end{tabular}

TABLE 2: Sequence of severe accident.

\begin{tabular}{lc}
\hline Events & Time (s) \\
\hline SBLOCA, containment pool crack, DHRS failed & 500 \\
Reactor tripped & 500 \\
PCV-SRVs open started & 10204 \\
Active core region actually exposed & 46900 \\
Gap release & 61650 \\
Core bottom dry out & 73095 \\
Core support plate failed & 300358 \\
Lower head breach & 457492 \\
PCV cavity breach & 482958 \\
Running ended & 1000000 \\
\hline
\end{tabular}

TABLE 3: Grouping of materials in the MELCOR.

\begin{tabular}{|c|c|c|c|}
\hline Class & Name & Representative & Member elements \\
\hline 1 & Noble gas & $\mathrm{Xe}$ & $\begin{array}{c}\text { Xe, Kr, Rn, He, Ne, Ar, } \\
\text { H, N }\end{array}$ \\
\hline 2 & Alkali metals & Cs & $\mathrm{Cs}, \mathrm{Rb}, \mathrm{Li}, \mathrm{Na}, \mathrm{K}, \mathrm{Fr}, \mathrm{Cu}$ \\
\hline 3 & Alkaline earths & $\mathrm{Ba}$ & $\begin{array}{c}\mathrm{Ba}, \mathrm{Sr}, \mathrm{Be}, \mathrm{Mg}, \mathrm{Ca}, \mathrm{Ra}, \mathrm{Es}, \\
\text { Fm }\end{array}$ \\
\hline 4 & Halogens & I & I, Br, F, CI, At \\
\hline 5 & Chalcogens & $\mathrm{Te}$ & Te, Se, S, O, Po \\
\hline 6 & Platinoids & $\mathrm{Ru}$ & $\begin{array}{c}\mathrm{Ru}, \mathrm{Pd}, \mathrm{Rh}, \mathrm{Ni}, \mathrm{Re}, \mathrm{Os}, \mathrm{Ir}, \\
\mathrm{Pt}, \mathrm{Au}\end{array}$ \\
\hline 7 & $\begin{array}{l}\text { Early transition } \\
\text { elements }\end{array}$ & Mo & $\begin{array}{c}\text { Mo, Tc, Nb, fe, Cr, Mn, } \\
\text { V, co, Ta, W }\end{array}$ \\
\hline 8 & Tetravalent & $\mathrm{Ce}$ & $\begin{array}{c}\mathrm{Ce}, \mathrm{Zr}, \mathrm{Th}, \mathrm{Np}, \mathrm{Ti}, \mathrm{Hf}, \mathrm{Pa} \text {, } \\
\mathrm{Pu}, \mathrm{C}\end{array}$ \\
\hline 9 & Trivalents & $\mathrm{La}$ & $\begin{array}{c}\text { La, Pm, Sm, Y, Pr, Nd, } \\
\text { Al, Sc, Ac, Eu, Gd, Cf, } \\
\text { Tb, Dy, Ho, Er, Tm, Yb, } \\
\text { Lu, Am, Cm, Bk }\end{array}$ \\
\hline 10 & Uranium & $\mathrm{U}$ & $\mathrm{U}$ \\
\hline 11 & $\begin{array}{l}\text { More volatile } \\
\text { main group }\end{array}$ & $\mathrm{Cd}$ & $\begin{array}{c}\mathrm{Cd}, \mathrm{Hg}, \mathrm{Zn}, \mathrm{As}, \mathrm{Pb}, \mathrm{Sb} \text {, } \\
\text { TI, Bi }\end{array}$ \\
\hline 12 & $\begin{array}{l}\text { Less volatile } \\
\text { main group }\end{array}$ & Sn & $\mathrm{Ga}, \mathrm{Ge}, \mathrm{Sn}, \mathrm{Ag}, \mathrm{In}$ \\
\hline 13 & Boron & B & $\mathrm{B}, \mathrm{Si}, \mathrm{P}$ \\
\hline 14 & Water & $\mathrm{H}_{2} \mathrm{O}$ & $\mathrm{H}_{2} \mathrm{O}$ \\
\hline 15 & Concrete & - & - \\
\hline 16 & Cesium iodide & CsI & CsI, - , - \\
\hline
\end{tabular}

in the pressure vessel is mainly produced by zirconiumwater reaction. The chemical equation of the zirconiumwater reaction is as follows:

$$
\mathrm{Zr}+2 \mathrm{H}_{2} \mathrm{O} \longrightarrow \mathrm{ZrO}_{2}+2 \mathrm{H}_{2}+\Delta \mathrm{HR},
$$

where $\Delta \mathrm{HR}$ is the heat per mole generated by zirconium after oxidation.

The time change of hydrogen release in the containment is shown in Figure 5. In the course of the accident, the fuel temperature gradually increased, the fuel rods swelled, and the zircon cladding was oxidized. Hydrogen was produced at around 11,820 s. Zirconium and water reacted slowly, and a small amount of the hydrogen was released during the next $1,500 \mathrm{~s}$. At $46,700 \mathrm{~s}$, the release of hydrogen reached the minimum value of $8.665 \mathrm{~kg}$. At this time, it could be determined that the reactor core was completely exposed. After $46,700 \mathrm{~s}$, the zirconium-water reaction became very violent, and hydrogen production increased rapidly. At the time of $240,250 \mathrm{~s}$, due to the failure in the core support plate, hydrogen release reached the peak value of $248.567 \mathrm{~kg}$. The released hydrogen shared less than $4 \%$ of the air volume, so no hydrogen explosion would occur.

4.2. Research on Radionuclide Release and Migration. The radioactive fission products such as radioactive iodine, cesium, xenon, and barium will be released from the reactor during a severe accident. This will pose a threat to the lives of the staff and the surrounding public and cause serious pollution to the ecological environment. The personnel in the cabin will be exposed to radiation, and radionuclides will be released into the environment and the ocean. Therefore, three radionuclides having relatively important influences on the radioactive consequences were selected as the research objects. These were the inert gas represented by Xe, the volatile fission products represented by CsI, and the nonvolatile fission products represented by $\mathrm{Ba}$.

4.2.1. Analysis of Release and Migration of Inert Gases Represented by Radionuclides Xe. Inert gases such as Xe are chemically stable and do not react with other nuclides. The release and migration behaviors of the radioactive nuclide Xe during the accident were analyzed. The pressure relief valve in the pressure vessel opened, and the reactor core began to be exposed at 10,204 s. The inert gas was mainly released from the reactor core, and the initial release time of radionuclide $\mathrm{Xe}$ in the primary circuit system and containment was $12,120 \mathrm{~s}$. The reactor core exposure time was lagged by $1,916 \mathrm{~s}$. Since the inert gas did not deposit on the surface of the thermal components and was insoluble in water, the released inert gas quickly entered the main system pipeline, the containment atmosphere, and the environment through a breach. The release process of radionuclides such as $\mathrm{Xe}$ in the primary circuit system, the cavity, and the containment is shown in Figures 6-8.

Xe began to be released in the primary circuit, and the mass of release was $0.298 \mathrm{~kg}$ at $12,120 \mathrm{~s}$. Table 2 shows that the full exposure time of the reactor core was $46,900 \mathrm{~s}$, and 


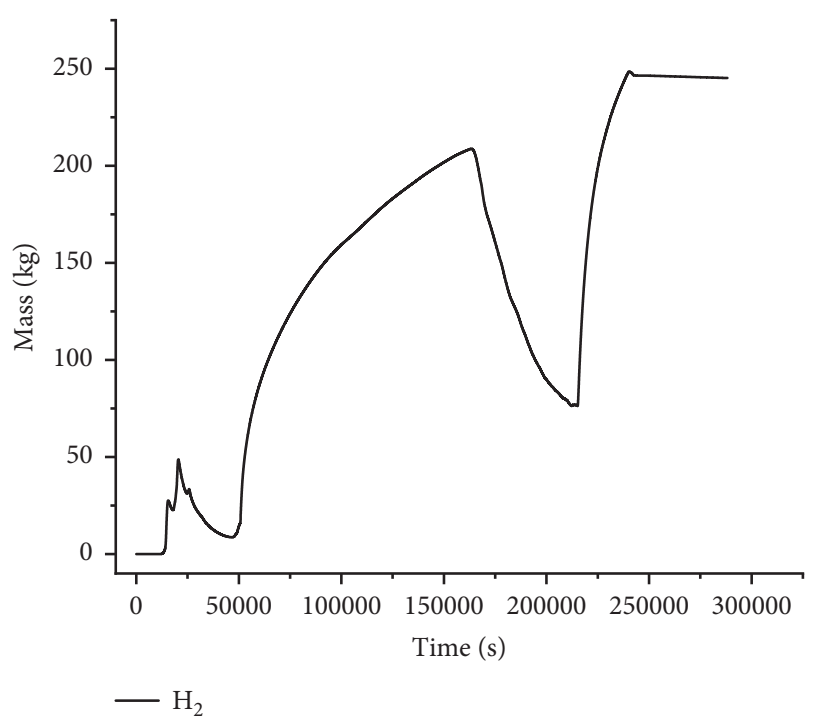

Figure 5: Hydrogen release from containment over time.

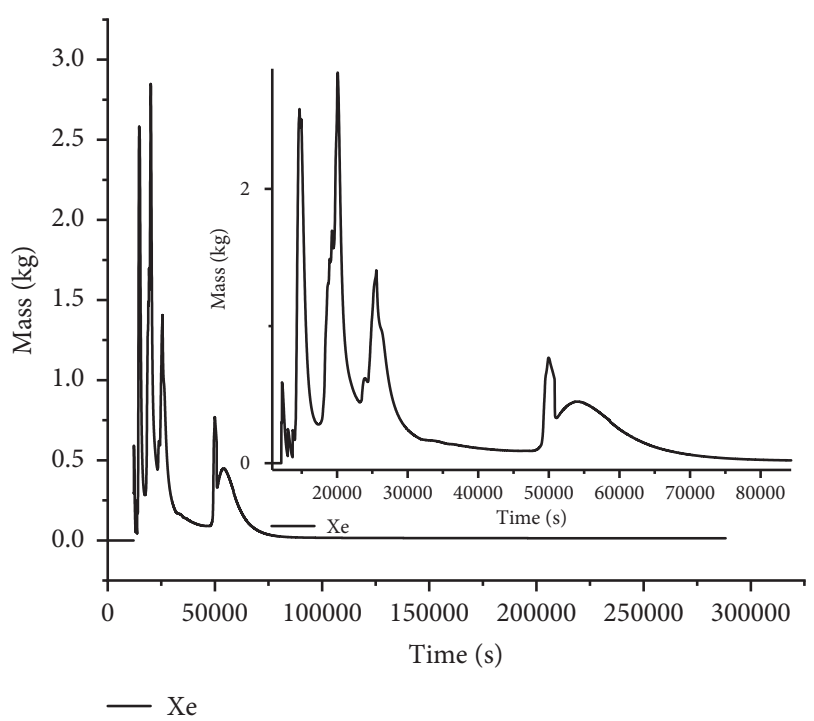

FIGURE 6: Release of Xe in the primary circuit system.

Figure 6 shows that the released amount of Xe decreased to the lowest value at $47,410 \mathrm{~s}$. The simulation results showed that the complete core exposure time delay was $510 \mathrm{~s}$. At $12,120 \mathrm{~s}$, Xe was released in the initial containment atmosphere (Figure 8), and the release amount was nearly 0 . Xe release decreased to the lowest value, and the reactor core was completely exposed at $47,600 \mathrm{~s}$. Xe began to release in the cavity (Figure 7), and the release amount was very small at the $14,690 \mathrm{~s}$. Because the reactor core was completely exposed, the rupture position was far away from the reactor cavity. The release amount of Xe increased sharply to the peak value of $0.616 \mathrm{~kg}$ at $50,820 \mathrm{~s}$ and then dropped sharply.

4.2.2. Analysis of Release and Migration of Volatile Gas Represented by Radionuclide CsI. The chemical properties of iodine are more active, and it immediately reacts with $\mathrm{Cs}$ to

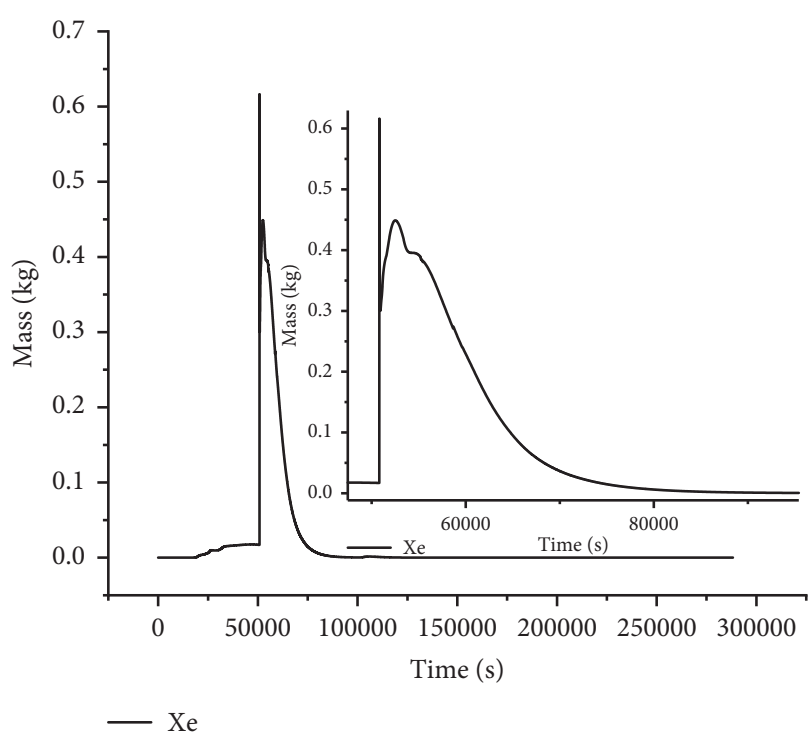

Figure 7: Release of Xe in cavity.

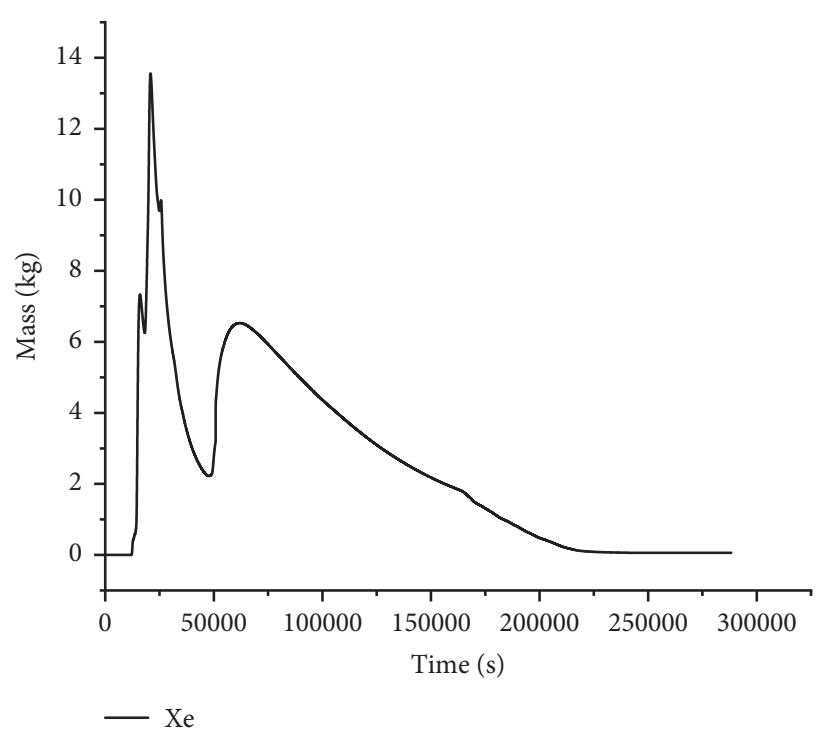

FIgURE 8: Release of Xe in containment.

form CsI which is easy to volatilize forming aerosols. Almost all the iodine released from the reactor core react with Cs to form CsI [1, 7], and the fraction of the element iodine is extremely small. The release of iodine in the containment is shown in Figure 9, and the comparison between iodine and CsI released in the containment is shown in Figure 10.

The release process of CsI in the primary circuit system and the cavity is shown in Figures 11 and 12. The CsI began to release in the primary circuit system, and the reactor core began to be exposed at 12,120 s. The release rate of CsI in the primary circuit system was high, and the mass of release was large with the peak value of $0.243 \mathrm{~kg}$, until the core was completely exposed and the release dropped to the minimum value (nearly 0 ).

The total mass of CsI released in the cavity (Figure 12) was much less with the maximum value of $0.0166 \mathrm{~kg}$ only. 


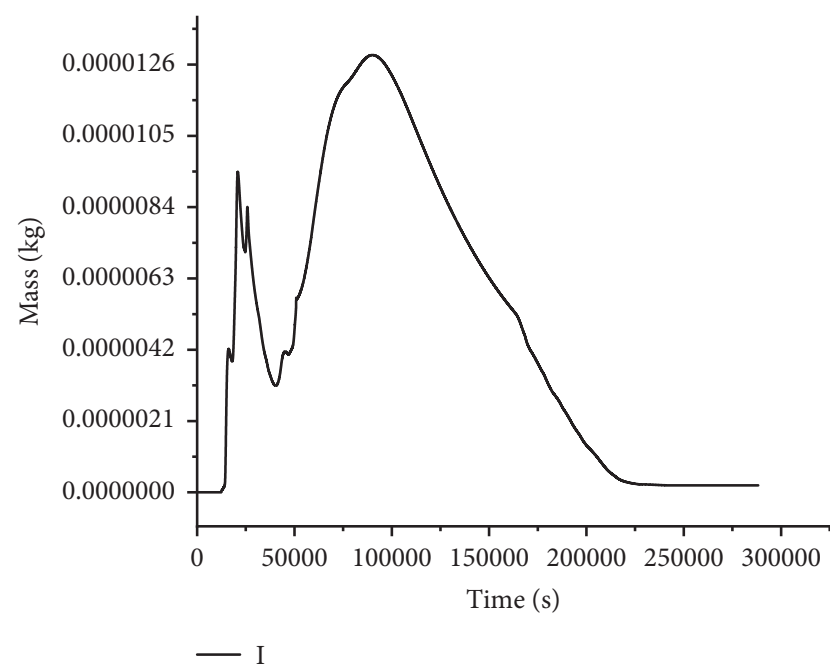

FIgURE 9: Release of I in the containment.

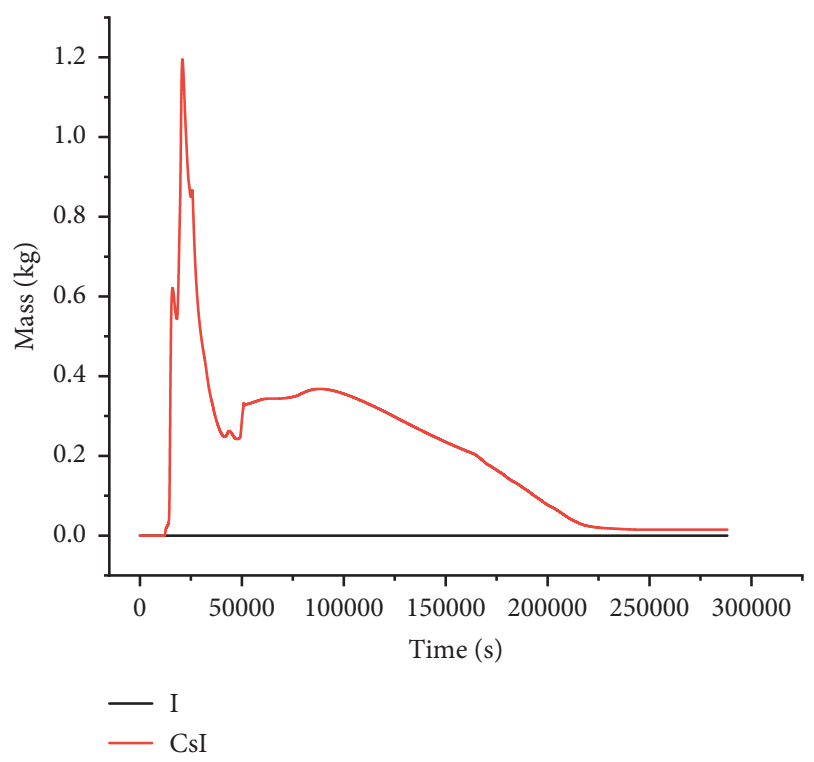

Figure 10: Comparison of I and CsI.

The release of CsI in the containment (Figure 10) sharply increased to the maximum value of $1.195 \mathrm{~kg}$ at first and then sharply decreased to the minimum value. The release showed a horizontal curve and remained at about $0.01 \mathrm{~kg}$ when the accident sequence was $226,500 \mathrm{~s}$. The main reason was that most of the CsI released into the containment were dissolved in the containment pool in the ionic state. A small part existed in the containment atmosphere in the form of aerosols, and minimal part was adsorbed on the surfaces of the thermal components in the containment. CsI aerosols in the containment atmosphere were gradually settled into the pool.

4.2.3. Analysis of Release and Migration of Nonvolatile Gases Represented by Radionuclide $\mathrm{Ba}$. Ba is a representative element of nonvolatile radionuclides. According to

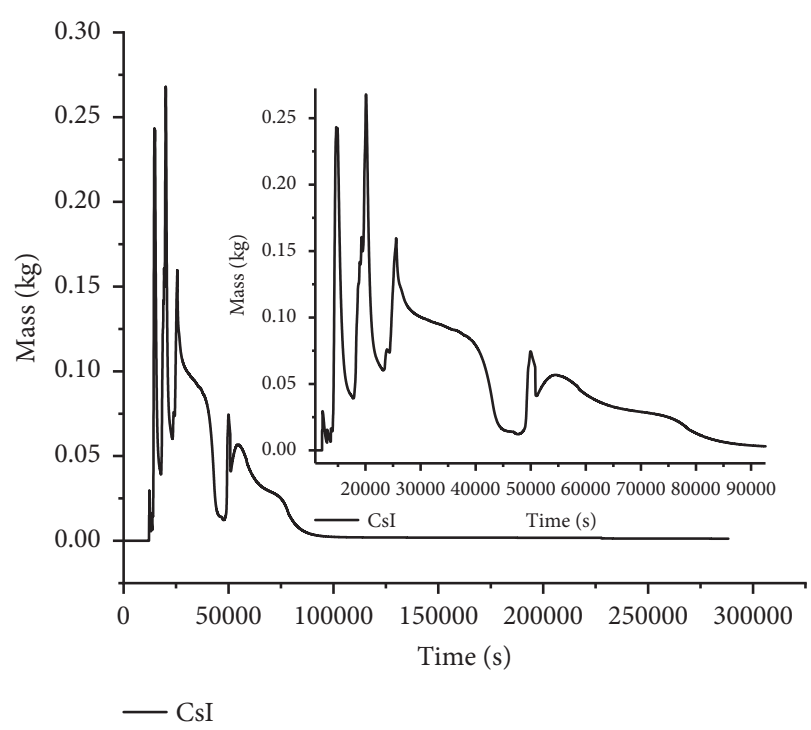

FIGURE 11: Release of CsI in the primary circuit system.

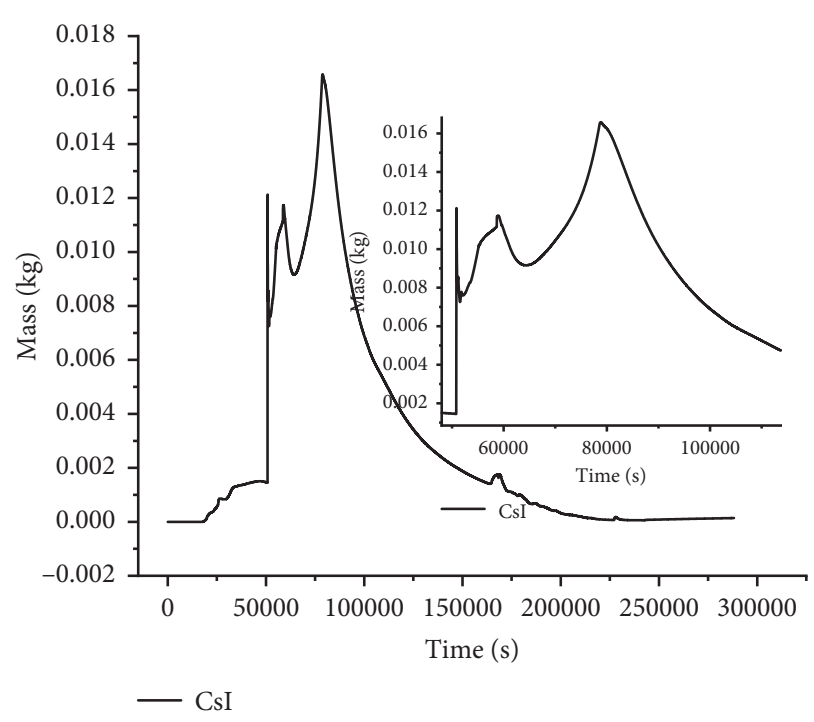

FIGURE 12: Release of CsI in the cavity.

MELCOR's calculation results, the nonvolatile radionuclides are the release amount of $\mathrm{Ba}$. Radionuclide $\mathrm{Ba}$ was selected as the representative of nonvolatile fission products to analyze its release and migration behavior. Ba was released in the reactor core during the core damage process at first. The release processes of radionuclide $\mathrm{Ba}$ in the primary circuit system, the containment, and the cavity during the accident process are shown in Figures 13-15.

$\mathrm{Ba}$ began to be released in the primary circuit system at $12,120 \mathrm{~s}$ and reached the maximum value of $0.434 \mathrm{~kg}$ at $58,660 \mathrm{~s}$ (Figure 13). Then, the release of $\mathrm{Ba}$ decreased continuously until dropped to $0.01 \mathrm{~kg}$ at $121,390 \mathrm{~s}$. Afterward, the mass of release $\mathrm{Ba}$ was extremely small and remained unchanged. Ba began to be released in the containment at $12,120 \mathrm{~s}$ (Figure 14). Its released amount increased rapidly and reached the maximum value of $1.48 \mathrm{~kg}$ and dropped at a similar rate until the reactor core was 


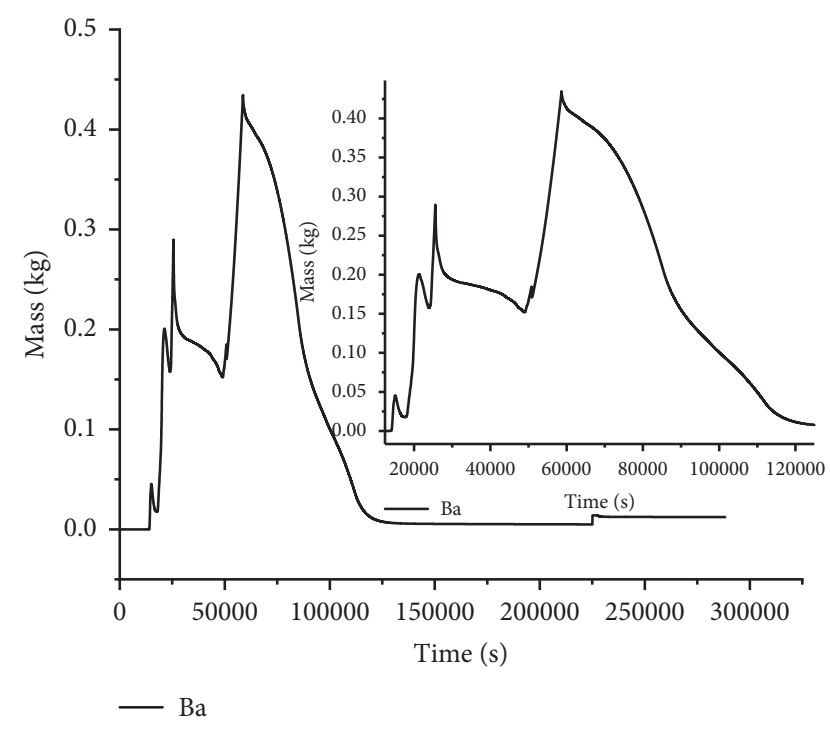

FIgURE 13: Release of $\mathrm{Ba}$ in the primary circuit system.

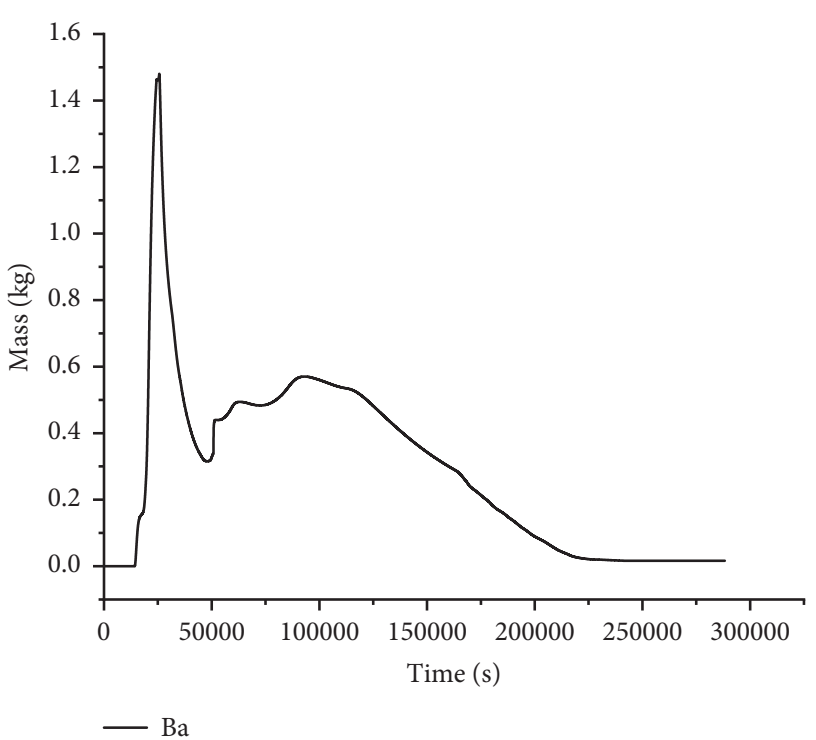

Figure 14: Release of $\mathrm{Ba}$ in the containment.

completely exposed at $48,000 \mathrm{~s}$. Finally, it dropped to the lowest value of $0.31 \mathrm{~kg}$. Due to the failure in the core support plate, the release of radionuclides increased to the peak value of $0.57 \mathrm{~kg}$ at $93,420 \mathrm{~s}$ and then slowly decreased. Compared with the primary circuit system and the containment, the released amount of $\mathrm{Ba}$ in the cavity (Figure 15) was relatively small and the maximum value was $0.0558 \mathrm{~kg}$.

\subsubsection{Analysis of Release of $\mathrm{Xe}, \mathrm{CsI}$, and $\mathrm{Ba}$ at Different Locations}

(1) Comparative Analysis of the Releases of Xe, CsI, and Ba in the Primary Circuit System. The releases of Xe, CsI, and $\mathrm{Ba}$ in the primary circuit system (Figures 6, 11 and 13) were

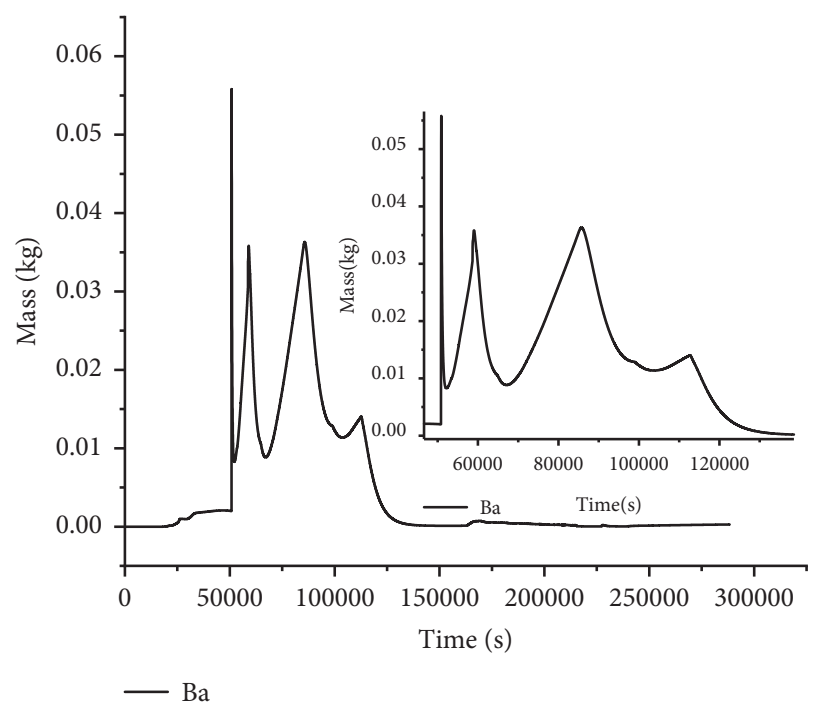

FIgURE 15: Release of $\mathrm{Ba}$ in the cavity.

compared and analyzed. These three radionuclides started to be released at the same time in the primary circuit system. Xe and CsI had similar release trends with the accident sequence. Before the reactor core was completely exposed, the releases of Xe and CsI showed a trend of 5 wave peaks, and troughs for the core nodes were divided into 5 radial rings. Assuming that the core was completely exposed at $46,900 \mathrm{~s}$, the wave trough times of the 5th segment released by Xe and CsI in the primary circuit system were $47,410 \mathrm{~s}$ and $47,730 \mathrm{~s}$, respectively. However, the release trend of $\mathrm{Ba}$ in the primary circuit system was different from those of Xe and CsI because most of $\mathrm{Ba}$ was deposited or settled on the surfaces of thermal components in the form of particles, while a small part of $\mathrm{Ba}$ was in the water and the minimal part of it was in the form of aerosol in the air.

(2) Comparative Analysis of the Releases of Xe, CsI, and $\mathrm{Ba}$ in the Containment. A comparative analysis of the releases of Xe, CsI, and $\mathrm{Ba}$ in the containment was performed (Figures 8, 10, and 14). The curves showing the time change of the releases of $\mathrm{Xe}$, CsI, and $\mathrm{Ba}$ were similar. These three radionuclides showed the same release trends in the containment, and the initial release time was $12,120 \mathrm{~s}$. But the release of Xe was much higher than that of CsI. Figures 8 and 10 show that the releases of Xe and CsI increased rapidly, and the times when they reached the first peak were $15,980 \mathrm{~s}$ and $16,030 \mathrm{~s}$, respectively. The peak value of the release at those timing was $7.329 \mathrm{~kg}$ and $0.621 \mathrm{~kg}$, respectively. Subsequently, the release continued to increase rapidly reaching the second peak values of $13.557 \mathrm{~kg}$ and $1.195 \mathrm{~kg}$ at 20,850 s and 20,860, respectively. Figure 14 shows that the release of $\mathrm{Ba}$ increased rapidly with time and reached its maximum value at 25,680 s. This release gradually decreased after reaching the maximum value with the continuous release of fission products from the molten core. After $220,000 \mathrm{~s}$, the releases of the three radionuclides reached the minimum value, and the release tended to become the horizontal curves. 


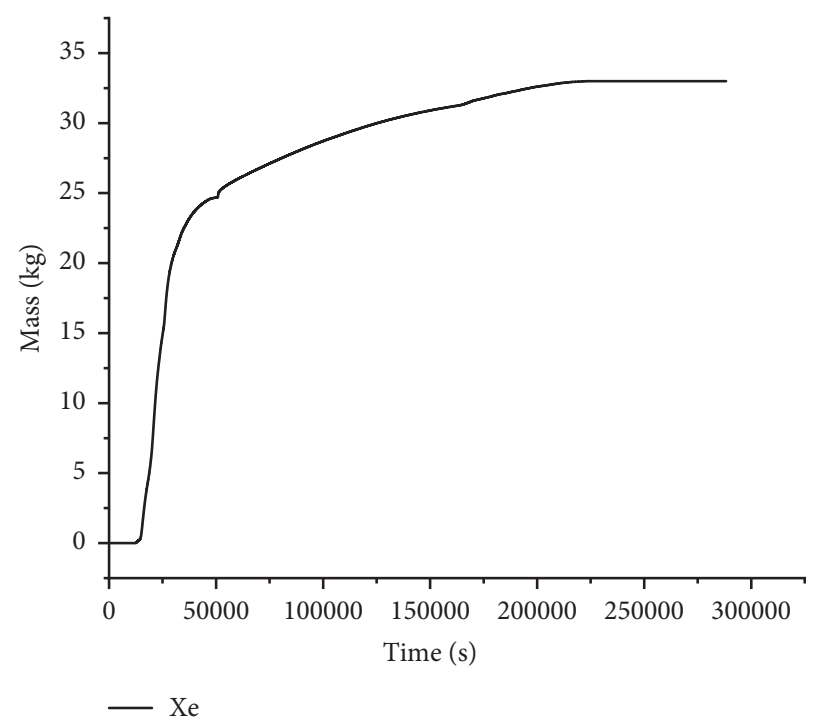

Figure 16: Release of $\mathrm{Xe}$ in the environment.

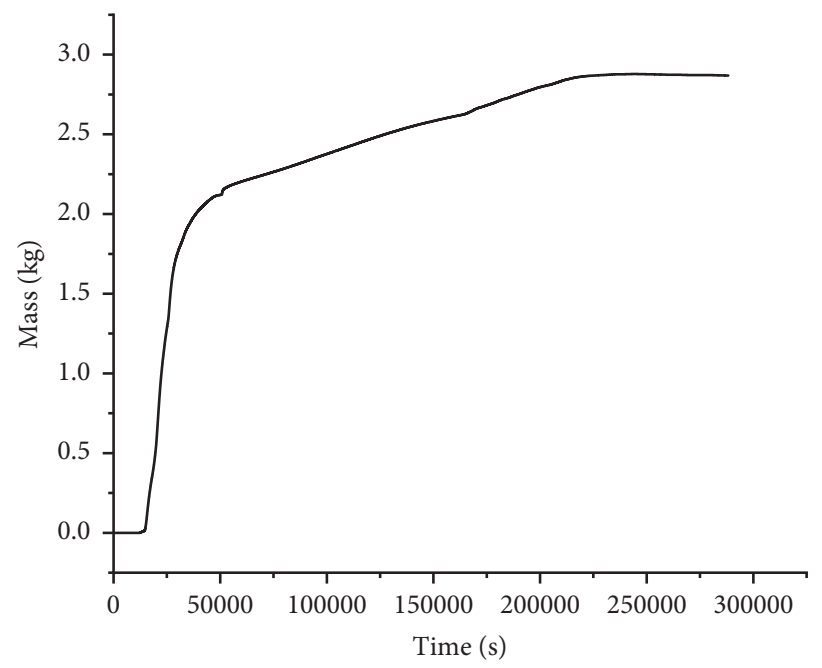

- CsI

Figure 17: Release of CsI in the environment.

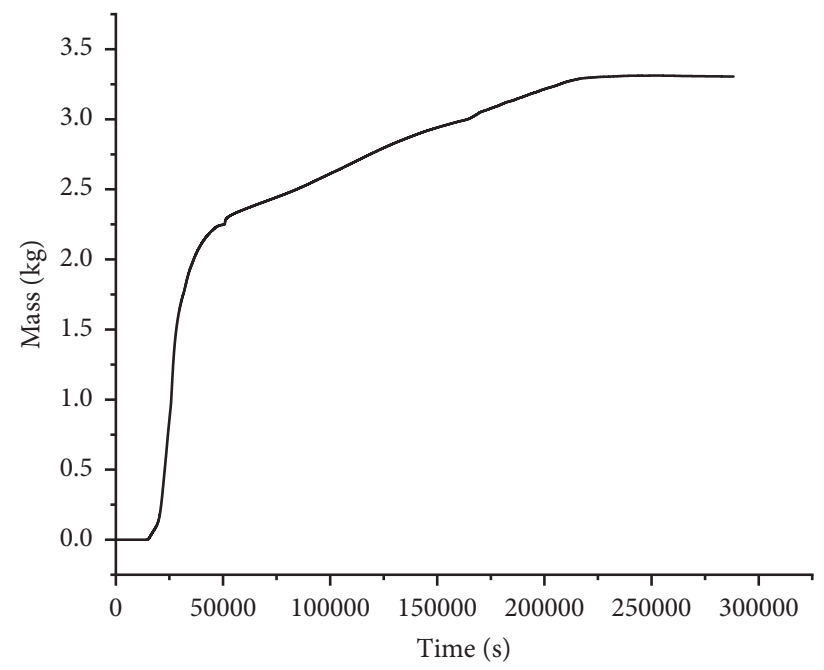

$-\mathrm{Ba}$

Figure 18: Release of $\mathrm{Ba}$ in the environment. 


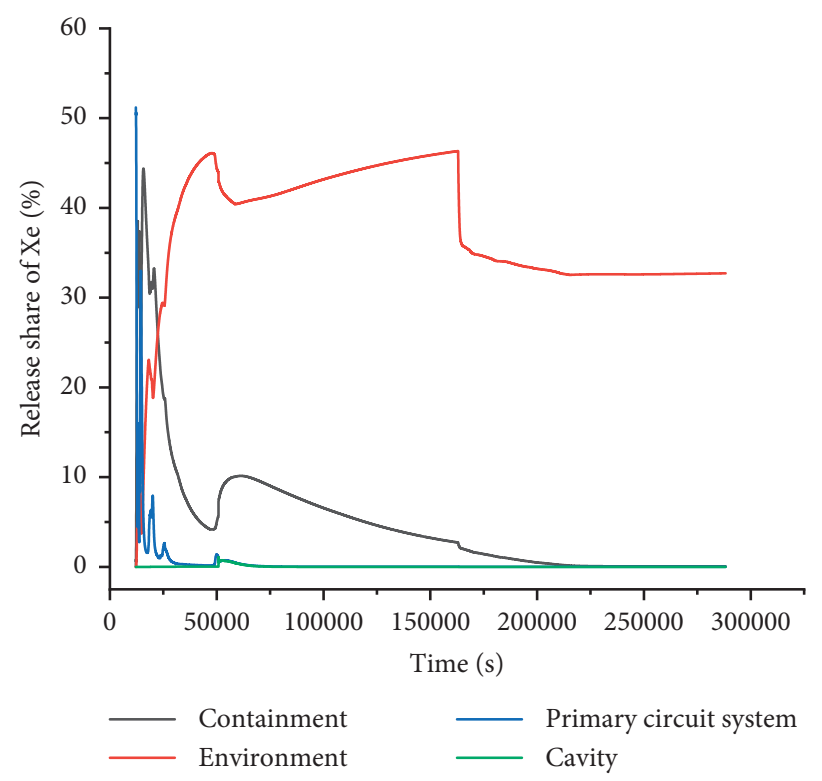

Figure 19: Distribution of Xe in different position.

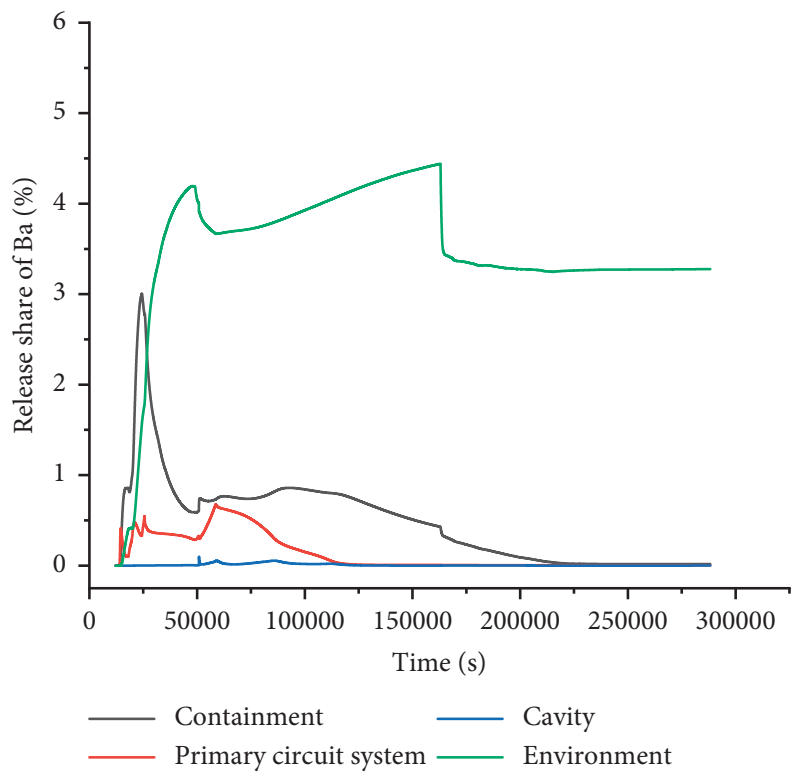

Figure 20: Distribution of $\mathrm{Ba}$ in different position.

(3) Comparative Analysis of the Releases of Xe, CsI, and Ba to the Environment. A comparative analysis of the releases of $\mathrm{Xe}, \mathrm{CsI}$, and $\mathrm{Ba}$ to the environment was performed (Figures 16-18). The three curves show the same trend, but the release of Xe to the environment was higher than those of $\mathrm{CsI}$ and $\mathrm{Ba}$. The releases of these three radionuclides to the environment started at the same time and increased sharply. The three radionuclides simultaneously passed through an inflection point at $50,810 \mathrm{~s}$ because the reactor core was completely exposed. The releases of the radionuclides continued to increase slowly because the calculation time was long enough. The releases of the three radionuclides to the environment reached the maximum value at $222,920 \mathrm{~s}$ and came into the horizontal transition state afterward. Almost all of the three radionuclides were released into the environment.

4.3. Analysis of Release Shares of Xe, CsI, and $\mathrm{Ba}$. The release shares of $\mathrm{Xe}, \mathrm{Ba}$, and $\mathrm{Csl}$ in the containment, the reactor cavity, the primary circuit system, and the environment are shown in Figures 19-21, respectively. The results show that the release shares of $\mathrm{Xe}, \mathrm{CsI}$, and $\mathrm{Ba}$ under the same conditions were similar. At the end of the calculation, the release shares of Xe in the primary circuit system, the containment, and the environment were $0.013 \%, 0.06 \%$ and $32.71 \%$, 


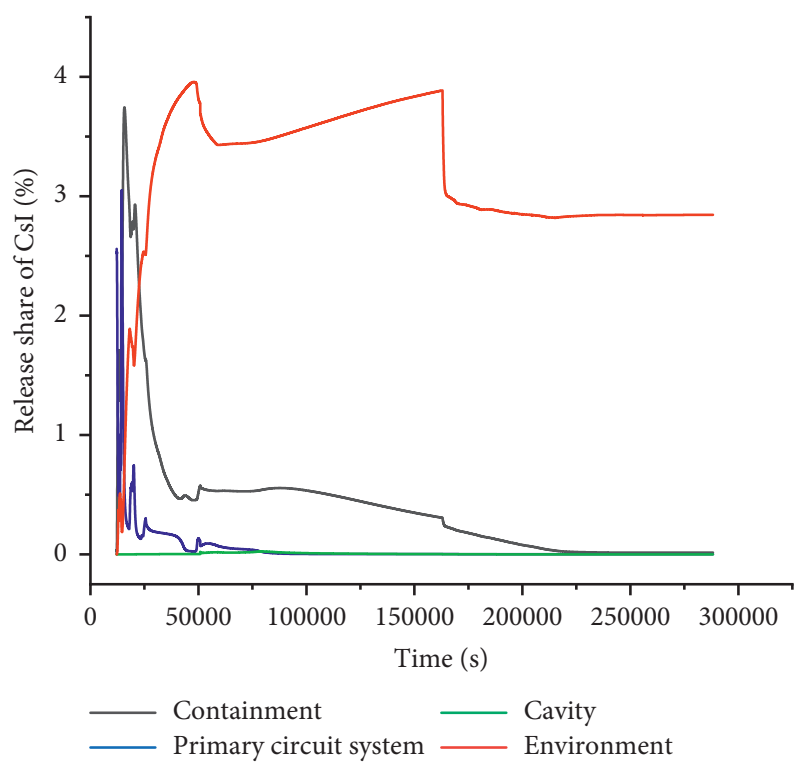

Figure 21: Distribution of CsI in different position.

TABLE 4: Distribution of radionuclide release share of fully exposed core.

\begin{tabular}{lcccc}
\hline & \multicolumn{4}{c}{ Share (\%) } \\
Radionuclide & Containment & $\begin{array}{c}\text { Primary } \\
\text { circuit } \\
\text { system }\end{array}$ & Cavity & Environment \\
& & 0.168 & 1.075 & 43.964 \\
$\mathrm{Xe}$ & 4.164 & 0.678 & 0.0296 & 4.005 \\
$\mathrm{Ba}$ & 0.599 & 0.0229 & 0.0036 & 3.7 \\
$\mathrm{CsI}$ & 0.454 & & & \\
\hline
\end{tabular}

TABLE 5: Distribution of maximum radionuclide release share.

\begin{tabular}{lcccc}
\hline & \multicolumn{4}{c}{ Share (\%) } \\
Radionuclide & Containment & $\begin{array}{c}\text { Primary } \\
\text { circuit } \\
\text { system }\end{array}$ & Cavity & Environment \\
& 44.391 & 51.195 & 1.075 & 46.331 \\
$\mathrm{Xe}$ & 3.003 & 0.678 & 0.0966 & 4.44 \\
$\mathrm{Ba}$ & 3.745 & 3.048 & 0.0252 & 3.957 \\
$\mathrm{CsI}$ & & & & \\
\hline
\end{tabular}

respectively; those of Ba were $0.016 \%, 0.0032 \%$, and $3.28 \%$, respectively; and those of CsI were $0.0145 \%, 0.0012 \%$, and $2.845 \%$, respectively. However, the release shares of these three radionuclides in the cavity were almost 0 .

To provide useful data for the dose assessment in the cabin during a severe accident, the release share distributions of the three radionuclides in the containment, the cavity, the primary circuit system, and the environment were analyzed for the timing of the complete exposure of the reactor core. The results are shown in Table 4 . The distributions of the maximum release shares of the three radionuclides during a severe accident were also analyzed, and the results are shown in Table 5 .

Table 5 represents the maximum release share of radionuclides at different locations with the progress of a severe accident. The maximum release share of $\mathrm{Xe}$ in the containment at $\mathrm{T} 1$ is $44.391 \%$, the maximum release share of $\mathrm{Xe}$ in the primary circuit system at T2 is $51.195 \%$, the maximum release share of Xe in the cavity at $\mathrm{T} 3$ is $1.075 \%$, and the maximum release share of Xe in the reactor cavity at $\mathrm{T} 4$ is $46.331 \%$. T1, T2, T3, and T4 represent different times.

The small break loss of coolant accident in a marine reactor directly resulted in the radioactive hazards to the atmospheric environment and the people inside the ship. The radiation effect in the adjacent cabin was very serious. The staff in this environment absorbed more systemic dose and thyroid dose, which caused serious harm to the human body. However, the radiation consequences in other cabins were less, and the radiation dose less affected the workers' health.

\section{Conclusion}

Based on the analyses on the release, migration, and retention characteristics and the distribution of radionuclides induced by SBLOCA in a marine reactor, the following conclusions are drawn:

(1) The analysis results of hydrogen source term released during a severe accident showed that the hydrogen release reached a peak value of $248.567 \mathrm{~kg}$ at $240,250 \mathrm{~s}$ due to the failure in the core support plate. But the hydrogen release volume accounted for less than $4 \%$ of the air volume, and there would be no possibility of the occurrence of hydrogen explosion accidents.

(2) The releases of Xe, CsI, and Ba in the primary circuit system, the containment, the reactor cavity, and the environment showed similar trends. The release of Xe in the primary circuit system was analyzed using the MELCOR. The results showed that complete core exposure was lagged by $510 \mathrm{~s}$, and the initial release time of the radionuclides was lagged by $1,916 \mathrm{~s}$. 
(3) The release shares of $\mathrm{Xe}, \mathrm{CsI}$, and $\mathrm{Ba}$ in the primary circuit system, the containment, the reactor cavity, and the environment were similar. When the calculation time was long enough, the release shares of these three radionuclides in the environment were the largest, followed by the containment, while the release shares in the primary circuit system and the reactor cavity were almost 0 .

(4) The releases of radionuclides reached the minimum values when the core was completely exposed. At that timing, the releases of $\mathrm{Xe}$ in the primary circuit system and the containment vessel were $0.0895 \mathrm{~kg}$ and $2.22252 \mathrm{~kg}$, respectively; those of $\mathrm{Ba}$ were $0.1521 \mathrm{~kg}$ and $0.31493 \mathrm{~kg}$, respectively; and those of CsI were $0.0122 \mathrm{~kg}$ and $0.24234 \mathrm{~kg}$, respectively.

(5) At the end of the calculation, the release shares of the $\mathrm{Xe}$ in the primary circuit system, the containment, and the environment were $0.013 \%, 0.06 \%$, and $32.71 \%$, respectively; those of Ba were $0.013 \%, 0.06 \%$, and $32.71 \%$, respectively; and those of CsI were $0.0145 \%, 0.0012 \%$, and $2.845 \%$, respectively.

\section{Data Availability}

The data used to support the findings of this study are included within the article.

\section{Conflicts of Interest}

The authors declare that they have no conflicts of interest.

\section{References}

[1] Y. Zhang, F. Zhang, X. Zhao, and Y. Zheng, "Source term analysis in severe accident induced by large break loss of coolant accident coincident with ship blackout for ship reactor," Atomic Energy Science and Technology, vol. 47, no. 9, pp. 1565-1571, 2013.

[2] B. Wu, M. Jia, and J. Gong, "Character and calculation method of nuclear accident source term of marine reactor," Journal of Naval University of Engineering, vol. 15, no. 5, pp. 87-90, 2003.

[3] X. Lyu, S. Liu, K. Ji, Y. Feng, S. Wang, and Z. Huang, "Research on hydrogen risk and hydrogen control system in marine nuclear reactor," Annals of Nuclear Energy, vol. 141, p. 107373, 2020.

[4] K. Ouyang, W. Chen, and Z. He, "Analysis of the radioactive atmospheric dispersion induced by ship nuclear power plant severe accident," Annals of Nuclear Energy, vol. 127, pp. 395-399, 2019.

[5] W. Wang, L. S. Chen, F. Zhan, and H. P. Liu, "Radioactive analysis on accident of SG-tube rupture coupled with whole ship blackout," Atomic Energy Science and Technology, vol. 49, no. 5, pp. 871-876, 2015.

[6] W. Wang, L. Chen, F. Zhan, and Q. Cai, "Source term analysis on blackout accident of marine reactor," Atomic Energy Science and Technology, vol. 48, no. 6, pp. 1038-1043, 2014.

[7] F. Zhan, F. Zhan, W. Wang, and L. Yu, "Analysis of accident due to interruption of power supply and safety valve failure," Journal of Naval University of Engineering, vol. 26, no. 6, pp. 37-41, 2014.
[8] R. M. Summers, MELCOR 1.8.1 Computer Code Manual Volume 1: Primer and Package Users Guides, MELCOR Primer, Sandia National Laboratories, Albuquerque, USA, 1991.

[9] L. E. Poier Baez, J. E. Nunez Mac Leod, and J. H. Baron, "Severe accident improvements for Carem-25 to arrest reactor vessel meltdown sequences," in Proceedings of the 10th International Conference on Nuclear Engineering, Arlington, VA, USA, April 2001.

[10] J. C. Kim, G. H. Jung, J. S. Cho, and H. C. Kim, "Severe accident analyses for SMART using MELCOR 1. 8.6 code," in Proceedings of the KNS autumn meeting, Daejeon, Republic of Korea, October 2011.

[11] R. M. Summers, MELCOR Computer Code manuals, Volume 1: RadioNuclide (RN) Package Users' guide, Sandia National Laboratories, Albuquerque, USA, 2000.

[12] L. Li, T. W. Kim, Y. Zhang et al., "MELCOR severe accident analysis for a natural circulation small modular reactor," Progress in Nuclear Energy, vol. 100, pp. 197-208, 2017. 